Digitalizacja archiwalnych numerów czasopisma naukowego Analecta Cracoviensia 1-24 (1969-1992)

i ich publikacja w otwartym dostępie - zadanie finansowane w ramach umowy 672/P-DUN/2017 ze środków

Ministra Nauki i Szkolnictwa Wyższego przeznaczonych na działalność upowszechniającą naukę

\title{
W POSZUKIWANIU PIERWSZEJ PRZYCZYNY Z POMOCĄ LOGIKI FORMALNEJ
}

Tytułem artykułu nawiązuję w sposób oczywisty do powszechnie znanego dzieła ks. prof. K. Kłósaka ${ }^{1}$. Poszukiwania moje ograniczają się jednakże tylko do Pierwszej Przyczyny Sprawczej ${ }^{2}$. Staram się mianowicie poddać logicznej analizie i ocenie argument za istnieniem Boga „ex ratione causae efficientis" z Summa Theologica I, q. 2, a. 3 św. Tomaisza z Ak'winu. W rezultacie, przedistawione niżej badania potwied'zają również na drodze zabiegów formalizacyjnych obydwa twierdzenia ks. Kłósaka:

1) „,..że tezę o niemożliwości regreśu w nieskończoność w obrębie przyczyn sprawczych (...) należy zastąpić zasadą racji dostatecznej (...)" oraz

2) ,...iż te wywody przestają być argumentacją odrębmą od argumenactji ex contingentia" 3 .

Biorąc za przedmiot badań odnośny tekst, naszą analizę logiczną możemy rozpocząć od zwrócenia uwagi na rodzaj i rozmieszczenie spójników inferencyjnych. Występowanie spójnika „więc" (lub jego synoni$\mathrm{mu}$ wykazuje, że zdania poprzedzające ten spójnik są przesłankami, a zdanie po nim występujące - wnioskiem. Natomiast spójnik „bo” (lub jego synonim) wiąże zdania w porządku odwrotnym (tzn. wniosek występuje przed a przesłanki po tym spójniku). Zdania, które są wyłącznie przesłankami, są uznane $\mathrm{w}$ tym przypadku bezpośrednio, są zatem aksjomatami względnie definicjami (w dalszym sensie). Ponieważ św. Tomasz we wspomnianym argumencie nie używa określeń w rodzaju „wydaje się", "być może” itp. lecz przeciwnie wypowiada swoje zdania z asercją (ze stanowczym uznaniem) rozumowania jego - jako nie hipotetyczne - podlegają ocenlie również z punktu widzenia prawomocności uznania przesłanek w przyjętym stopniu pewności, tzn. sprawdzeniu, czy

1 Kłósak (1955, 1957).

2 Zob. Kłósak (1961, 1973).

3 Kłósak (1973, s. 205). 
nie zawierają one przypadkiem błędu petitionis principii ${ }^{4}$. O takich przesłankach, których prawdziwość nie jest oczywista, a nawet przeciwnie wydaje się być wątpliwa, nie podolbna też twierdzić, że są one fałszywe; dlatego nie znajduję podstaw do mówienia o błędach materialnych w rozważanych tu rozumowaniach. Gdy bowiem możliwość prawdziwości wszystkich przesłanek nie jest wykluczona, a asercja niektórych wydaje się być wątpliwa, lepiej jest po prostu poprzestać na mówieniu tylko o braku uzasadnienia dla przesadnego stopnia pewności, z jakim się owe (wątpliwe) przesłanki uznaje. W niniejszym artykule pragnę poczynić pewne sugestie odnośnie do możliwości wyeliminowania z ,drugiej drogi" błędu petitionis principii.

Analizując tekst św. Tomasza pod względem jego logicznej budowy zdołamy nie tylko zakwalifikować poszczególne zdania do przesłanek, wniosków, aksjomatów, definicji i twierdzeń, ale również sprawdzić sugerowane w nim stosunki wynikania, a zatem ocenić tekst od strony jego poprawności logiczno-formalnej (czyli braku błędów non sequitur). Formalizacja tekstu jest przy tym jedynym możliwym dowodem jego logiczno-formalnej poprawności ${ }^{5}$. Tekst św. Tomasza jednak, jak każda wypowiedź języka naturalnego, zawiera zdania eliptyczne i rozumowania entymematyczne. Okoliczność ta sprawia, że formalizacja w tym przypadku w żadnym razie nie jest a być nie może jakąś zwykłą formą tłumaczenia języka naturalnego na język symboliczny, lecz jedynie jego interpretacją. Możemy więc na wstępie postawić pytanie, czy istnieje w ogóle w odpowiednim języku symbolicznym taka interpretacja odnośnego tekstu, przy której tekst ten okazuje się być wolny od błędów non sequitur, tzn. jest formalnie poprawny.

\section{PIERWSZA FORMALIZACJA}

Tekst ,drugiej drogi" zostanie tu zinterpretowany w pewnym prostym języku symbolicznym. W języku tym oprócz powszechnie znanych spójników logicznych i kwantyfikatorów wystąpią dwa rodzaje zmiennych nazwowych i kilka predykatów.

\section{Zmienne:}

4 ,Wnioskowanie, w którym przesłanki są uznane bez należytego uzasadnienia stopnia pewności, z jakim się je w tym wnioskowaniu uznaje, zawiera błąd, zwany petitio principii". Ajdukiewicz (1965, s. 107). Zob. też Williams (1960).

5 Mówiąc o formalizacji mam na uwadze dwa jej zasadniczo różne pojęcia: 1) próbę odnotowania jakiejś wypowiedzi języka naturalnego w języku symbolicznym lub 2) próbę wyrażenia w określonym języku symbolicznym pewnych przekonań. Występująca niżej pierwsza formalizacja Tomaszowego argumentu odpowiada pierwszemu z tych pojęć, zaś trzy pozostałe — drugiemu. 
$\mathrm{x}, \mathrm{y}, \mathrm{z}, \ldots$ reprezentują byty realne;

$\mathrm{n}, \mathrm{k}, \ldots$ reprezentują liczby naturalne $(1,2,3, \ldots)$ :

Skróty:

${ }^{\prime} \mathrm{Cxy}^{\prime}=:$ ' $\mathrm{x}$ jest przyczyną sprawczą $\mathrm{y}-\mathrm{a}^{\prime}{ }^{6}$;

$' \mathrm{x}<\mathrm{y}^{\prime}=$ : ' $\mathrm{x}$ wyprzedza $\mathrm{w}$ istnieniu $\mathrm{y}-\mathrm{a}$;

'Ix' =: 'x jest pierwszą przyczyną sprawczą' ('x jest Bogiem');

${ }^{\prime} \mathrm{Mx}^{\prime}=$ : ' $\mathrm{x}$ jest przyczyną pośrednią';

'Ux' $=$ : ' $\mathrm{x}$ jest przyczyną ostatnią';

${ }^{\prime} \mathrm{Px}^{\prime}=: \mathrm{x}^{\prime}$ jest przyczyną';

'Sx' $=$ : ' $\mathrm{x}$ jest skutkiem'.

(D1, A1) Invenimus enim in istis sensibilibus esse ordinem efficientium; [Odkrywamy, że wśród rzeczy zmysłowo postrzegalnych występuje uporządkowanie przyczyn sprawczych] ${ }^{7}$. (Zdanie to interpretuję za pomocą definicji indukcyjnej dla naturalnej potęgi relacji przyczynowości sprawczej i aksjomatu stwierdzającego przynależność każdego bytu realnego do pola owej relacji).

D1. $\left\{\begin{array}{l}C^{1} x y \Leftrightarrow C x y \\ C^{k+1} x y \Leftrightarrow \exists z\left(C^{k} x z \wedge C z y\right)\end{array}\right.$

Al. $\forall x \exists y \exists n\left(C^{n} y x \vee C^{n} y x\right)$

(T1) nec tamen invenitur, nec est possibile quod aliquid sit causa efficiens sui ipsius; [Nie znajdujemy jednak i jest to niemożliwe, aby coś było przyczyną sprawczą samego siebie] (twierdzenie)

T1. $\sim \exists \times \exists \mathrm{nC}^{\mathrm{n}} \mathrm{xx}$

(dowód nie wprost)

(1) quia [wówczas bowiem (gdyby coś było przyczyną sprawczą samego siebie)] (założenie dowodu nie wprost)

1. $\exists \mathrm{x} \exists \mathrm{nC}^{\mathrm{n}} \mathrm{xx}$, z.d.n.

$(2,3,4)$ esset prius seipso [byłoby wcześniejsze od samego siebie]

2. $\forall \mathrm{x} \forall \mathrm{y} \forall \mathrm{n}\left(\mathrm{C}^{\mathrm{n}} \mathrm{xy} \Rightarrow \mathrm{x}<\mathrm{y}\right)$, aksjomat $\mathrm{A} 2$

3. $\forall \mathrm{x} \forall \mathrm{n}\left(\mathrm{C}^{\mathrm{n}} \mathrm{xx} \Rightarrow \mathrm{x}<\mathrm{x}\right)$, bo 2

4. $\exists \mathrm{x} \mathrm{x}<\mathrm{x}$, bo 3 i 1

(5) quod est impossibile [a to jest niemożliwe]

5. $\sim \exists \mathrm{x} \mathrm{x}<\mathrm{x}$, aksjomat $\mathrm{A} 3$

sprzeczność: 4 i 5

(T2) Non autem est passibile quod in causis efficientibus procedatur in

${ }^{6}$ Przyjmuję tu, że relacja ,bycia przyczyną sprawczą" jest dwuczłonowa. Natomiast w Geach (1969, s. 83) przyjmuje się, że jest ona trójczłonowa: x sprawia, że y jest $\mathrm{A}$.

7 Uporządkowanie przyczyn sprawczych interpretuję jako ciąg bytów powiązanych ze sobą wielokrotnym iloczynem względnym (potęgą naturalną) relacji C. Jest to interpretacja spokrewniona $\mathrm{z}$ tą, która występuje w Wengret (1971), gdzie ów porządek oznacza mocno-ancestralne domknięcie relacji C. Występujące tu polskie tłumaczenie łacińskiego tekstu należy do ks. bpa- Bohdana Bejze i pochodzi z Bejze (1968, s. 8-9). 
infinitum [Nie jest zaś· rzeczą możliwą, by wśród przyczyn sprawczych można było iść w nieskończoność] (twierdzenie)

T2. $\sim \forall x \exists y \quad \exists n C^{n} y x$

(D2, D3, D4) quia in omnibus causis efficientibus ordinatis prium est causa medii, et medium est causa ultimi; sive media sint plura, sive unum tantum. [We wszystkich bowiem przyczynach uporządkowanycr. to, co pierwsze, jest przyczyną czynnika pośredniego, a pośrednie jesí przyczyną czynnika ostatniego, niezależnie od tego, czy przyczyn pośrednich jest wiele, czy tylko jedna] (trzy definicje)

D2. $\mathrm{Ix} \Leftrightarrow \exists \mathrm{y} \exists \mathrm{nC}^{\mathrm{n}} \mathrm{xy} \wedge \sim \exists \mathrm{z} \exists \mathrm{kC}^{\mathrm{k}} \mathrm{zx}$

D3. $\mathrm{Mx} \Leftrightarrow \exists \mathrm{y} \exists \mathrm{z} \exists \mathrm{n} \exists \mathrm{k}\left(\mathrm{C}^{\mathrm{n}} \mathrm{yx} \wedge \mathrm{C}^{\mathrm{k}} \mathrm{xz}\right)$

D4. $\mathrm{Ux} \Leftrightarrow \exists \mathrm{y} \exists \mathrm{nC}^{\mathrm{n}} \mathrm{yx} \wedge \sim \exists \mathrm{z} \exists \mathrm{kC}^{\mathrm{k}} \mathrm{xz}$

(D5, D6, L1) Remotc autem causa, removetur effectus. [Kiedy bowiem usunie się przyczynę, usuwa się i skutek] (dwie definicje i jeden lemat)

D5. $P x \Leftrightarrow \exists y \exists \mathrm{nC}^{\mathrm{n}} \mathrm{xy}$

D6. $\mathrm{Sx} \Leftrightarrow \exists \mathrm{y} \exists \mathrm{nC}^{\mathrm{n}} \mathrm{yx}$

L1. $\sim \exists \mathrm{xSx} \Leftrightarrow \sim \exists \mathrm{yPy}$

[bo: $\exists x S x \Leftrightarrow \exists x \exists y \exists n C^{n} y x \Leftrightarrow \exists y \exists x \exists n C^{n} y x \Leftrightarrow \exists y P y$ ]

(A4, L2) Ergo, si non feurit primum in causis efficientibus, non erit ultimum, nec medium. [Przeto gdyby wśród przyczyn sprawczych nie było przyczyny pierwszej, nie byłoby ani ostatniej, ani pośredniej] (aks,jomat i lemat)

A4. $(\sim \exists \mathrm{xSx} \Leftrightarrow \sim \exists \mathrm{yPy}) \Rightarrow[\sim \exists \mathrm{xIx} \Rightarrow \sim \exists \mathrm{y}(\mathrm{Uy} \vee \mathrm{My})]$

L2. $\sim \exists x I x \Rightarrow \sim \exists y(U y \vee M y)$, bo A4 i L1

(Dowód nie wprost dla twierdzenia T2:)

(1) Sed si procedatur in infinitum in causis efficientibus [Jeśliby wśród przyczyn sprawczych szło się w nieskończoność] (założenie dowodu nie wprost)

1. $\forall x \exists y \exists n C^{n} y x$, z.d.

(2) non erit prima causa efficiens; [wówczas nie byłoby pierwszej przyczyny sprawczej]

2. $\sim \exists x I x$, boD2 i 1

(3) et sic non erit nec effectus ultimus, nec causae efficientes mediae; [a wobec tego nie byłoby ani ostatecznego skutku, ani przyczyn sprawczych pośrednich;]

3. $\sim \exists y$ (Uy $\vee$ My), bo L2 i 2

(4) quod potest esse falsum. [jest zaś oczywiste, że przypuszczenie tego byłoby fałszem]

4. ヨy (Uy $\vee \mathrm{My})$, bo A1, D3, D4

sprzeczność: 3,4

(T3) Ergo est necesse ponere aliquam causam efficientem primam, quam omnes Deum nominant. [Z konieczności więc uznać należy jakąś przy- 
czynę sprawczą pierwszą, ktọ́rą wszyscy nazywamy Bogiem.] (twierdzenie)

T3. ヨxIx, bo T2, A1, D2.

W ten sposób tekst został sformalizowany, a tym samym równiez wykazana jego logiczno-formalna poprawność. Przy pomocy tejże formalizacji została określona rola poszczególnych zdań w procesie uzasadniania podstawowej tezy i dowiedzione niewystępowanie błędów non sequitur. Z pomocą tego formalizmu możemy również pokazać, że argument Tomaszowy opiera się w zasadzie na jednym założeniu o naturze ogólnej:

(1) $\sim \exists x I x \Rightarrow \sim \exists y$ (Uy $\vee$ My), czyli:

(2) $\exists y(\mathrm{Uy} \vee \mathrm{My}) \Rightarrow \exists \mathrm{xIx}$.

Wobec definicji D2, D3 i D4 oczywistą jest również implikacja odwrotna: (3) $\exists x I x \Rightarrow \exists y$ (Uy $\vee M y)$.

Oznacza to, że w argumencie Tomaszowym obowiązuje równoważność: (4) $\exists x I x \Leftrightarrow \exists y$ (Uy $\vee$ My).

Wobec tej równoważności wystarczy z faktu niepustości relacji przyczynowości sprawczej od razu wnosić o istnieniu przyczyny pierwszej. Wy eksponowanie tego podstawowego założenia $w$ formie (4) ujawnia zatem trywialność samego argumentu i jego uwikłanie w petitio principii. Najprościej byłoby ten argument zapisać w postaci wnioskowania:

$\exists \mathrm{xIx} \Leftrightarrow \exists \mathrm{x} \exists \mathrm{yCxy}$

$\exists x \exists y C x y$

$\mathrm{xIx}$

Niepodobna jednak dostrzec dostatecznych podstaw do uznania aksjo matu A4 [lub założeń w formie (1), (2) lub (4)] akurat w sposób niepo wątpiewalny, czyli z asercją.

\section{DRUGA FORMALIZACJA}

Autorem następnej formalizacji ,drugiej drogi", jak dotąd (o ile mi wiadomo) pierwszej i jedynej opublikowanej formalizacji tego argumentu, jest prof. Wilhelm K. Essler. Została ona wyłożona w Essler (1969 s. $223-227)$.

Skróty:

'Wxy' $=$ : 'x jest przyczyną sprawczą y-a'; ${ }^{\prime} \mathrm{EUxy} \mathrm{X}^{\prime}=$ : ' $\mathrm{x}$ jest pierwszą przyczyną $\mathrm{y}-\mathrm{a}$

Aksjomaty:

Ax1. $\exists y \exists x W x y$

Ax2. $\forall y(\sim \exists z E U z y \Rightarrow \sim \exists x W x y)$

Ax3. $\forall \mathrm{x} \sim \mathrm{Wxx}$

Ax4. $\forall \mathrm{x} \forall \mathrm{y}[\mathrm{x} \neq \mathrm{y} \wedge \sim \mathrm{Wxy} \wedge \sim \mathrm{Wyx} \Rightarrow \exists \mathrm{z}(\mathrm{Wzx} \wedge \mathrm{Wzy})]$

6 - Analecta Cracoviensia 
Definicja:

D1. $\forall \mathrm{x} \forall \mathrm{y}(\mathrm{EUxy} \Leftrightarrow \mathrm{Wxy} \wedge \forall \mathrm{z} \sim \mathrm{Wzx})$

Twierdzenia ${ }^{8}$ :

T1. $\sim \forall \mathrm{x} \exists \mathrm{y}(\mathrm{x} \neq \mathrm{y} \wedge \mathrm{Wyx})$, bo:

1. $\forall \mathrm{x} \exists \mathrm{y}(\mathrm{x} \neq \mathrm{y} \wedge \mathrm{Wyx})$, założenie dowodu nie wprost

2. $\exists y \exists x W x y, A x 1$

3. $\forall y(\sim \exists z E U z y \Rightarrow \sim \exists x W x y), A x 2$

4. $\sim \exists z E U z a \Rightarrow \sim \exists x W x a$, bo 3

5. $\exists x W x a \Rightarrow \exists z E U z a$, bo 4

6. $\exists x W x a$, bo 2

7. $\exists z E U z a$, bo 5,6

8. EUba, bo 7

9. $\forall \mathrm{x} \forall \mathrm{y}(\mathrm{EUxy} \Leftrightarrow \mathrm{Wxy} \wedge \forall \mathrm{z} \sim \mathrm{Wzx}), \mathrm{D} 1$

10. Wba $\wedge \forall \mathrm{z} \sim \mathrm{Wzb}$, bo 9,8

11. $\forall \mathrm{z} \sim \mathrm{Wzb}$, bo 10

12. $\sim \mathrm{Wcb}$, bo 11

13. $\exists y(b \neq y \wedge \mathrm{Wyb})$, bo 1

14. $\mathrm{b} \neq \mathrm{c} \wedge \mathrm{Wcb}$, bo 13

15. Wcb, bo 14

sprzeczność: 15,12

.T2. $\exists \mathrm{x}\{\sim \mathrm{Wxx} \wedge \forall \mathrm{y}(\mathrm{x} \neq \mathrm{y} \Rightarrow \mathrm{Wxy} \wedge \sim \mathrm{Wyx}) \wedge \forall \mathrm{z}[\sim \mathrm{Wzz} \wedge \forall \mathrm{y}$ $(\mathrm{z} \neq \mathrm{y} \Rightarrow \mathrm{Wzy} \wedge \sim \mathrm{Wyz}) \Rightarrow \mathrm{z}=\mathrm{x}]\}$, bo:

1. $\exists y \exists x W x y, A x 1$

2. $\forall \mathrm{x} \sim \mathrm{Wxx}, \mathrm{Ax} 3$

3. $\forall y(\sim \exists z E U z y \Rightarrow \sim \exists x W x y), A x 2$

4. $\forall \mathrm{x} \forall \mathrm{y}[\mathrm{x} \neq \mathrm{y} \wedge \sim \mathrm{Wxy} \wedge \sim \mathrm{Wyx} \Rightarrow \exists \mathrm{z}(\mathrm{Wzx} \wedge \mathrm{Wzy})], \mathrm{Ax} 4$

5. $\sim \forall \mathrm{x} \exists \mathrm{y}(\mathrm{x} \neq \mathrm{y} \wedge \mathrm{Wyx})$, bo 1,3 (T1)

6. $\exists \mathrm{x} \forall \mathrm{y} \sim(\mathrm{x} \neq \mathrm{y} \wedge \mathrm{Wyx})$, bo 5

7. $\forall y \sim(a \neq y \wedge$ Wya $)$, bo 6

8. $\sim(\mathrm{a} \neq \mathrm{y} \wedge \mathrm{Wya})$, bo 7

$1.1 \mathrm{a} \neq \mathrm{y}, \mathrm{z}$. dod. (założenie dodatkowe)

$1.2 \sim$ Wya, bo 8 i 1.1

1.1.1 W Way, z. dod.

1.1.2 a $\neq$ y $\wedge \sim$ Way, bo 1.1 i 1.1 .1

1.1.3 a $\neq$ y $\wedge \sim$ Way $\wedge \sim$ Wya, bo 1.1 .2 i 1.2

1.1.4 $\exists z$ (Wza $\wedge \mathrm{Wzy})$, bo 4 i 1.1 .3

1.1.5 Wba $\wedge$ Wby, bo 1.1.4

1.1.6 Wba, bo 1.1.5

a1. $a=b, z$. dod.

8 Dowody W. K. Esslera przekształciłem wedle sposobu jaki jest na naszym gruncie znany np. z Borkowski (1970). 


\section{a2. Waa, bo $1.1 .6 \mathrm{i}$ a1}

a3. $\sim$ Waa, bo 2

sprzecz.: a2, a3

1.1.7 $\mathrm{a} \neq \mathrm{b}$, bo $\mathrm{al} \Rightarrow$ sprzecz.

1.1.8 $\sim(\mathrm{a} \neq \mathrm{b} \wedge \mathrm{Wba})$, bo 7

1.1.9 $\sim$ Wba, bo 1.1 .8 i 1.1 .7

sprzecz.: 1.1 .6 i 1.1 .9

1.3 Way, bo $1.1 .1 \Rightarrow$ sprzecz.

1.4. Way $\wedge \sim$ Wya, bo 1.3 i 1.2

9. $\mathrm{a} \neq \mathrm{y} \Rightarrow$ (Way $\wedge \sim$ Wya), bo $1.1 \Rightarrow 1.4$

10. $\forall y(a \neq y \Rightarrow$ Way $\wedge \sim$ Wya $)$, bo 9

11. $\sim$ Waa $\wedge \forall y(a \neq y \Rightarrow$ Way $\wedge \sim$ Wya $)$, bo 2,10

$2.1 \sim \mathrm{Wzz} \wedge \forall \mathrm{y}(\mathrm{z} \neq \mathrm{y} \Rightarrow \mathrm{Wzy} \wedge \sim \mathrm{Wyz}), \mathrm{z}$ : dod.

$2.2 \forall y(z \neq y \Rightarrow$ Wzy $\wedge \sim$ Wyz $)$, bo 2.1

2.1.1 $\mathrm{z} \neq \mathrm{a}, \mathrm{z}$. dod.

2.1.2 Wza $\wedge \sim$ Waz, bo 2.2 i 2.1 .1

2.1.3 Wza, bo 2.1.2

2.1.4 $\mathrm{a} \neq \mathrm{z}$, bo 2.1 .1

2.1.5 Waz $\wedge \sim \mathrm{Wza}$, bo 10 i 2.1 .4

2.1.6 $\sim$ Wza, bo 2.1.5

sprzecz.: 2.1 .6 i 2.1 .3

2.3 $\mathrm{z}=\mathrm{a}$, bo $2.1 .1 \Rightarrow$ sprzecz.

12. $\sim \mathrm{Wzz} \wedge \forall \mathrm{y}(\mathrm{z} \neq \mathrm{y} \Rightarrow \mathrm{Wzy} \wedge \sim \mathrm{Wyz}) \Rightarrow \mathrm{z}=\mathrm{a}$, bo $2.1 \Rightarrow 2.3$

13. $\forall \mathrm{z}[\sim \mathrm{Wzz} \wedge \forall \mathrm{y}(\mathrm{z} \neq \mathrm{y} \Rightarrow \mathrm{Wzy} \wedge \sim \mathrm{Wyz}) \Rightarrow \mathrm{z}=\mathrm{a}]$, bo 12

14. $\sim$ Waa $\wedge \forall \mathrm{y}(\mathrm{a} \neq \mathrm{y} \Rightarrow$ Way $\wedge \sim \mathrm{Wya}) \wedge \forall \mathrm{z}[\sim \mathrm{Wzz} \wedge \forall \mathrm{y}(\mathrm{z} \neq \mathrm{y} \Rightarrow$ $\Rightarrow$ Wzy $\wedge \sim \mathrm{Wyz}) \Rightarrow \mathrm{z}=\mathrm{a}$ ], bo 11 i 13

15. $\exists \mathrm{x}\{\sim \mathrm{Wxx} \wedge \forall \mathrm{y}(\mathrm{x} \neq \mathrm{y} \Rightarrow \mathrm{Wxy} \wedge \sim \mathrm{Wyx}) \wedge \forall \mathrm{z}[\sim \mathrm{Wzz} \wedge \forall \mathrm{y}$ $(\mathrm{z} \neq \mathrm{y} \Rightarrow \mathrm{Wzy} \wedge \sim \mathrm{Wyz}) \Rightarrow \mathrm{z}=\mathrm{x}]\}$, bo 14 .

Również w tej formalizacji akcjomaty Ax2 i Ax4 wymagają dalszych uzasadnień. Ax2 zakłada (podobnie jak A4), że nie istniałby w świecie realnym żaden skutek, jeśliby nie było pierwszej przyczyny sprawczej. Aksjomat Ax4 zakłada dodatkowo, iż relacja ,przyczynowego sprawiania" jest multyplikatywną quasi-półstrukturą ${ }^{9}$ Że owe aksjomaty stwierdzają właśnie „to, co jest”, należałoby dopiero ujawnić na gruncie meta-

9 W teorii algebr Boole'a używa się terminu „struktura” (,siatka”, „krata”) na oznaczenie relacji słabo-porządkującej (czyli zwrotnej, antysymetrycznej i przechodniej zarazem), w której dla każdej pary elementów jej pola istnieje supremum (najmniejşze ograniczenie górne) i infimum (największe ograniczenie dolne). Jeżeli zaś każdạ para elementów pola relacji słabo-porządkującej posiada infimum, to powiadamy, że ta relacja jest półstrukturą multyplikatywną. Quasi-półstruktura multyplikatywna to taka dowolna relacja, która spełnia ten tylko warunek, że każda para elementów jej pola posiada ograniczenie dolne (i może nie posiadać infimum) 
fizyki i jakiegoś doświadczenia. W przeciwnym razie ten sformalizowany dowód na istnienie Boga albo jest hipotetyczny albo uwikłany w petitio principii.

\section{TRZECIA FORMALIZACJA}

Z kolei przedstawiam pewną sformalizowaną próbę wyeliminowania (czy też choćby osłabienia) w „drugiej drodze" błędu petitionis principii z. pomocą zasady dostatecznej racji bytu.

Skróty:

${ }^{\prime} \mathrm{Cxy}^{\prime}=$ : ' $\mathrm{x}$ jest przyczyną sprawczą $\mathrm{y}-\mathrm{a}^{\prime}$; ' $\mathrm{x}<\mathrm{y}^{\prime}=$ : ' $\mathrm{x}$ wyprzedza $\mathrm{w}$ istnieniu $\mathrm{y}-\mathrm{a}$ ';

${ }^{\prime} \mathrm{Rxy}^{\prime}=:$ ' $\mathrm{x}$ jest racją istnienia $\mathrm{y}-\mathrm{a}$ ';

'Sxy' =: 'x jest dostateczną racją istnienia $\mathrm{y}-\mathrm{a}$ ';

'Ix' = : 'x jest przyczyną sprawczą ('x jest Bogiem').

Aksjomaty i definicje:

A1. $\forall x \exists y(C x y \vee$ Cyx)

(Aḳsjomat ten stwierdza, że każdy byt realny należy do pola relacji C)

$$
\text { A2. } \forall x \forall y(C x y \Rightarrow x<y)
$$

(Jeżeli $\mathrm{x}$ jest przyczyną sprawczą $\mathrm{y}-\mathrm{a}$, to $\mathrm{x}$ wyprzedza $\mathrm{y}-\mathrm{a} \mathrm{w}$ istnieniu)

A3. $\sim \exists \mathrm{x} x<\mathrm{x}$

(Żaden byt nie wyprzedza $\mathrm{w}$ istnieniu samego siebie)

A4. $\forall x \forall y(C x y \Rightarrow R x y)$

(Każda przyczyna sprawcza jest zarazem racją bytu)

D1. $\mathrm{Sxy} \Leftrightarrow \operatorname{Rxy} \wedge \sim \exists z(z \neq x \wedge R z x) \wedge R x x$

(Dostateczha racja bytu to taki byt realny, który wyłącznie w sobie samym posiada rację swojego istnienia)

A5. $\forall x$ ヨySyx nihil est sine ratione

(Każdy byt posiada dostateczną rację swojego istnienia)

D2. $\mathrm{Ix} \Leftrightarrow \exists \mathrm{yCxy} \wedge \sim \exists \mathrm{zCzx}$

(Pierwsza przyczyna sprawcza jest to niesprawiona przyczyna spraw.cza) ${ }^{10}$

Twierdzenia: ,

T1. $\sim \exists \mathrm{xCxx}$, bo:

1. $\exists x C x x, z . d . n$.

2. $\forall x(C x x \Rightarrow x<x)$, bo $A 2$

3. $\exists \mathrm{x} x<\mathrm{x}$, bo 2,1

10 Pierwsza przyczyna sprawcza jest $w$ tym przypadku pojęta jako element minimalny $\mathrm{w}$ polu relacji $\mathrm{C}$. 
sprzecz: $3, \mathrm{~A} 3$

T2. $\sim \forall \mathrm{x} \exists \mathrm{yCyx}$, bo:

1. $\forall \mathrm{x} \exists y C y x$, z. d. n.

2. $\forall \mathrm{x} \exists y(\mathrm{y} \neq \mathrm{x} \wedge \mathrm{Ryx})$, bo $1, \mathrm{~T} 1, \mathrm{A4}$

3. $\forall z \exists x \mathrm{Sxz}, \mathrm{A} 5$

4. $\forall \mathrm{z} \exists \mathrm{x}[\mathrm{Rxz} \wedge \sim \exists \mathrm{y}(\mathrm{y} \neq \mathrm{x} \wedge \mathrm{Ryx}) \wedge \mathrm{Rxx}], \mathrm{D} 1,3$

5. $\exists \mathrm{x} \sim \exists \mathrm{y}(\mathrm{y} \neq \mathrm{x} \wedge$ Ryx), bo 4

6. $\sim \forall \mathrm{x} \exists \mathrm{y}(\mathrm{y} \neq \mathrm{x} \wedge \mathrm{Ryx})$, bo 5

sprzecz.: 2,6

T3. $\exists x I x$, bo:

1. $\exists \mathrm{x} \sim \exists \mathrm{yCyx}$, bo $\mathrm{T} 2$

$1.1 \sim \exists y \mathrm{Cyx}$, z. dod.

1.2 ЭуСху $\vee$ ЭуСух, bo A1

1.3 ЭyCxy, bo 1.2 i 1.1

1.4 ヨуСху $\wedge \sim \exists y C y x$, bo 1.3 i 1.1

1.5 Ix, bo D2 i 1.4

$1.6 \exists \mathrm{xIx}$, bo 1.5

2. $\exists x I x$, bo 1 i $1.1 \Rightarrow 1.6$

IV. FORMALIZACJA CZWARTA

W przypadku zastosowania zasady dostatecznej racji.bytu możnaby już $\mathrm{w}$ ogóle zrezygnować $\mathrm{z}$ wprowadzenia pojęcia przyczynowości sprawczej i ograniczyć się do przeprowadzenia prostego sformalizowanego dowodu na istnienie bytu koniecznego. Takie uproszczenie argumentu „drugiej drogi" daje w rezultacie pewną (Leibniza) wersję "trzeciej drogi" Skróty:

'Rxy' =: ' $x$ jest racją istnienia $y-a^{\prime}$;

'Sxy' =: 'x jest dostateczną racją istnienia $\mathrm{y}-\mathrm{a}$ ';

'Kx' = : ' $\mathrm{x}$ jest bytem koniecznym' ('x jest Bogiem').

Aksjomaty i definicje:

A1. $\exists x \exists y R x y$

D1. $\mathrm{Sxy} \Leftrightarrow \mathrm{Rxy} \wedge \sim \exists z(\mathrm{z} \neq \mathrm{x} \wedge \mathrm{Rzx}) \wedge \mathrm{Rxx}$

A2. $\forall x \exists y S y x$

D2. $\mathrm{Kx} \Leftrightarrow \mathrm{Sxx}$

Twierdzenie podstawowe:

T1. $\exists x K x$, bo:

1. $\exists x \exists y S x y$, bo A2

1.1 Sxy., z. dod.

$\left.\begin{array}{l}1.2 \underset{\operatorname{Rxx}}{\sim} \exists z(\mathrm{z} \neq \mathrm{x} \wedge \mathrm{Rzx}) \\ 1.3 \underset{\mathrm{Sxx}}{\mathrm{R}}\end{array}\right\}$ bo D1 i 1.1

$1.4 \mathrm{Sxx}$, bo $\mathrm{D} 1,1.3,1.2$ 


\section{2. $\forall x \forall y .(S x y, \Rightarrow S x x)$, bo $1.1 \Rightarrow 1.4$ \\ 3. $\exists x \mathrm{Sxx}$, bo 2 i 1 \\ 4. $\exists x K x$, bo 3 i D1}

\section{BIBLIOGRAFIA}

Ajdukiewicz, K.: Logika pragmatyczna, Warszawa 1965.

Bejze, B. bp (redaktor): Studia z filozofii Boga, Warszawa 1968.

Borkowski, L.: Logika formalna. Systemy logiczne. Wstęp do metalogiki, Warszawa 1970.

Essler, W. K.: Einführung in die Logik, Stuttgart 1969. 85.

Geach, P.: Causality and creation w: God and the soul, London 1969, s. 75-

Kłósak, K.: W poszukiwaniu Pierwszej Przyczyny, cz. I, Warszawa 1955; cz. II, Warszawa 1957.

Kłósak, K.: Dowód św. Tomasza z Akwinu na istnienie Boga z przyczynowości sprawczej. Analiza i próba krytycznej oceny, Roczniki Filozoficzne, 8 (1960) z. 1, Lublin 1961, s. 125-156.

Kłósak, K.:- Próba uwspółcześniania Tomaszowej argumentacji za istnieniem Boga z przyczynowości sprawczej w: Studia z filozofii Boga, t. II, Warszawa 1973. s. $204-222$.

Wengert, R. G.: The logic of essentially ordered causes w: 'Notre Dame Journal of Formal Logic 12 (1971), s. 406-422.

Williams, C. J. F.: Hic autem non est procedere in infinitum (St: Thomas Aquinas) w: Mind. 69 (1960), s. 403-405.

\section{AUF DER SUCHE NACH DER ERSTEN URSACHE MIT HILFE VON DER FORMALEN LOGIK}

\section{Zus a m menfassung}

Im vorligenden Aufsatz möchte ich die formale und materielle Gültigkeit des Gottesbeweises ,ex ratione causae efficientis" von Summa Theologica (I, q. 2, a. 3) des hl. Thomas von Aquin nachprüfen. Da ein Beweis formal korrekt ist, wenn er keinen non sequitur Fehler enthält, wollen wir den entsprechenden Text des hl. Thomas formalisieren. Eine Formalisierung, obwohl sie eine Übertragung einer natürlichen Sprache in eine formalisierte ist, kann nicht. als 'einfache Übersetzung, sondern nur als eine Art von Interpretation verstanden werden. So möchte ich zuerst zeigen, dass es Interpretationen des Textes von Thomas gibt, bei denen der Text logisch-formal fehlerfrei ist. Darüber hinaus möchte ich versuchen nachzuweisen, dass es auch eine solche Interpretation dieses Textes gibt, bei der eine petitio principii zu vermeiden moglich scheint. Die erte Formalisierung wird mit dem Text des hl. Thomas verglichen. Die zweite stammt von Prof. W. K. Essler. In der dritten und vierten versuche ich die petitio principii zu eliminieren. 